drain with side holes may be more effective in allowing access for air than the usual corrugated drain.

(4) The wound should be inspected daily.

(5) An hourly pulse chart should be kept and any sustained rise immediately reported. It is emphasized that this was the first sign in both the above patients.

If gas infection is suspected, vigorous treatment should be instituted:

(1) The wound should be widely opened and a swab taken for bacteriological examination.

(2) Blood transfusion should be commenced as soon as possible as these patients all have some degree of haemolysis.

(3) Penicillin should be given as above.

(4) Hyperbaric oxygen can be life-saving (Brummelkamp, Boerema \& Hoogendyk, 1963) though the salvage rate in these elderly arteriosclerotics will inevitably be disappointing. Until the patient can be placed in the oxygen pressurechamber, oxygen should be given by face-mask.

\section{Acknowledgments}

My thanks are due to Dr I. Howard, Medical Superintendent of the Alfred Hospital, Mr R. S. Lawson and Mr K. Bradley for permission to publish these case reports.

\section{References}

Brummelkamp, W.H., Boerema, I. \& Hoogendy K, L. (1963) Treatment of clostridial infections with hyperbaric oxygen drenching. Lancet, i, 235.

Gye, R. Rountree, P.M. \& Lowenthal, J. (1961) Infection of surgical wounds with Clostridium welchii. Med.J. Aust. i, 761 .

Ham, J.M., Mackenzie, D.C. \& Lowenthal, J. (1964) The immediate results of lower limb amputation for atherosclerosis obliterans. Aust. N.Z. J. Surg. 34, 97.

Karasewick, E.G., Harper, E.M., Sharp, N.C.C., Shields, R.S., Smith, G. \& McDowall, D.G. (1964) Hyperbaric oxygen in clostridial infections. Clinical Application of Hyperbaric Oxygen (Ed. by I. Boerema). Proceedings of the First International Congress, 1963, pp. 36-40. Elsevier, Amsterdam.

NAGLER, F.P.O. (1945) Treatment of experimental gas gangrene due to Clostridium welchii with penicillin and antitoxin. Brit. J. exp. Path. 26, 57.

\title{
Primary Raynaud's disease associated with sclerodactyly and digital osteosclerosis
}

\author{
D. N. GoldING \\ M.A., M.D., M.R.C.P.I. \\ H. BAKER \\ M.B., Ch.B., M.R.C.P. \\ Princess Alexandra Hospital, Harlow, and \\ St John's Hospital for Diseases of the Skin, London
}

The USUal skeletal lesion associated with primary Raynaud's disease, or with Raynaud's phenomenon secondary to another disorder such as progressive systematic sclerosis, is digital osteoporosis affecting particularly the terminal phalanges of the hands. Rarely there may be progression to osteolysis of the terminal phalanges associated with wasting of the pulp and beaking of the nails, which in systemic sclerosis may be accompanied by ulceration of the tips of the fingers, indolent paronychia and sometimes soft tissue calcification.

Increased bone density (osteosclerosis) of the metacarpals and phalanges is rarely found in association with Raynaud's disease, and is not mentioned in the majority of relevant textbooks. The following case is of interest because of the existence of both osteosclerosis and sclerodactyly, apparently secondary to Raynaud's disease.

\section{Case report}

A 45-year-old housewife stated that ever since childhood she had been prone to attacks of numbness and pallor followed by blueness and then redness of the hands, precipitated by cold. Her feet were affected to a lesser degree. The episodes were more severe in winter, when she regularly suffered from chilblains, but they occurred throughout the year. During adolescence she had observed wasting of the ulnar three fingers of the left hand, which progressed for a while and then became stationary. Lately she had noticed that the left hand was habitually colder and bluer than its fellow. 
There was no family history of Raynaud's disease, though many members of her family were prone to chilblains.

On examination, the hands were cyanosed and cool. There was marked wasting and slight flexion deformities of the left third, fourth and fifth fingers with dryness and slight thickening of the skin, especially on the flexor aspects of the digits. Although the finger pulps were wasted, the overlying skin was not bound down as in systemic sclerosis and could be wrinkled into folds, and there was no cutaneous ulceration. The feet appeared normal. Systemic examination revealed no abnormality, the arm pulses being equal and of normal volume. The blood pressure in the arms was $190 / 100 \mathrm{mmHg}$ and equal on both sides.

Radiographs of the hands (see Fig. 1) showed increased bone density in the shafts of the phalanges of both hands, especially the middle and terminal phalanges, this being particularly marked in the left ring and little fingers. There was some degree of juxta-articular osteoporosis, but no resorption of terminal phalanges nor any soft tissue calcification. Radiographs of the feet were normal, as were those of the forearm bones. The chest X-ray showed no abnormality. Electromyograms on the left and right abductor digiti minimi and first dorsal interosseus muscles showed no evidence of denervation or muscle ٌ fibre disorder. Motor nerve conduction velocities $\underset{\mathbb{Q}}{\overparen{2}}$

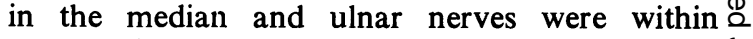
normal limits, but there was slight prolongation $c$ of sensory conduction time in the left ulnar $\overrightarrow{\vec{S}}$ nerve from the little finger to the wrist (latency $5.0 \mathrm{msec}$, normal maximum $3.5 \mathrm{msec}$ ). All other investigations were normal: $\mathrm{Hb} 90 \%\left(13.3 \mathrm{~g} / \frac{\bar{\sigma}}{\mathrm{c}}\right.$ $100 \mathrm{ml}$ ), WBC $6000 / \mathrm{mm}^{3}$ (normal differential), ESR $7 \mathrm{~mm} / \mathrm{hr}$ (Westergren), urine-normal, $\stackrel{\varrho}{\circ}$ blood urea $24 \mathrm{mg} / 100 \mathrm{ml}$, serum uric acid $3.3 \mathrm{mg} / 100 \mathrm{ml}$, latex and Rose-Waaler tests $\overrightarrow{0}$ negative, LE cells not found and test for anti- $\overrightarrow{\vec{H}}$ nuclear factor (ANF) negative.

\section{Comment}

This patient had primary Raynaud's disease as defined by attacks of pallor and numbness of the hands progressing to cyanosis and redness precipitated by the cold, absence of gangrene, onset early in life and no evidence of systemic o connective tissue disorder or any other disease (Allen \& Brown, 1932). More recently sclerodactyly (atrophic changes in the skin, subcutaneous tissues and muscles) had occurred insidiously, $\stackrel{\ulcorner}{\gtrless}$ particularly affecting the ulnar three fingers of $\vec{\varphi}$ the left hand.

Although localized para-articular osteoporos 15 was present, the striking bone change in the digito

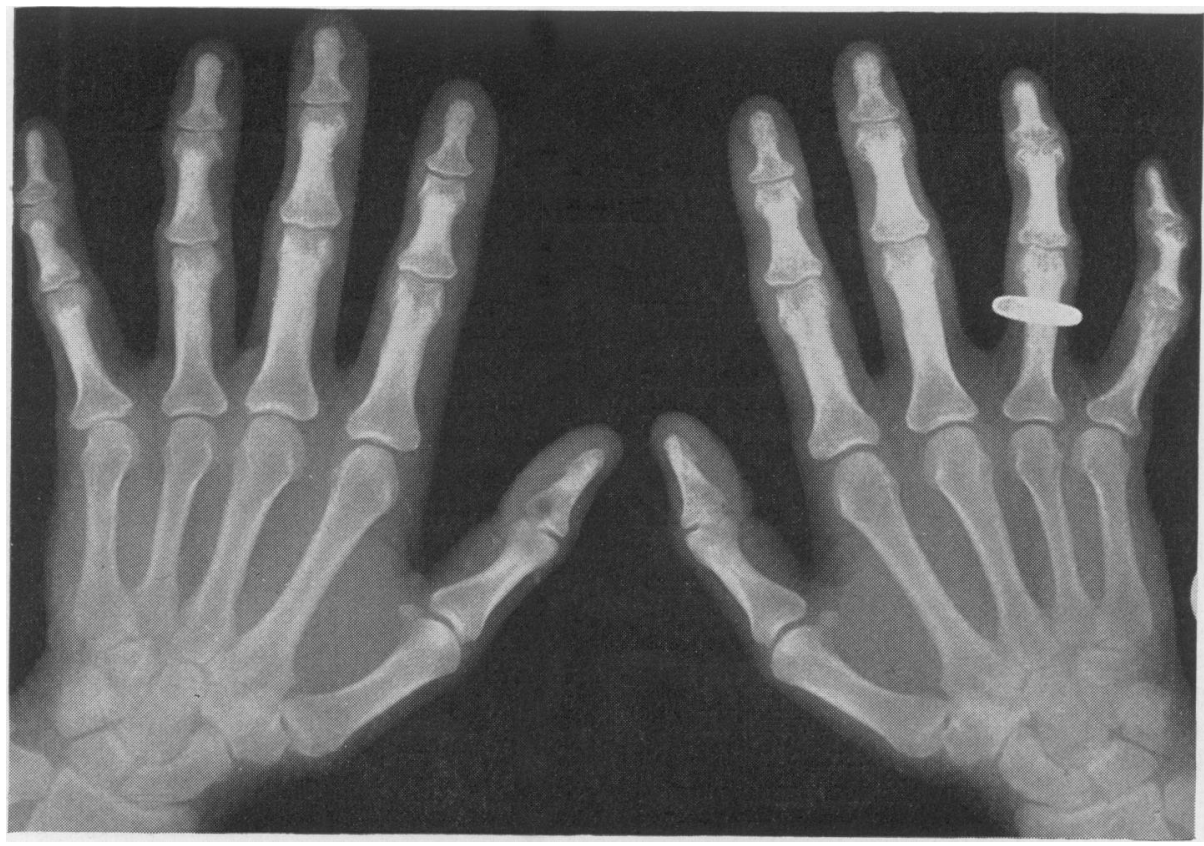

FIG. 1. Radiograph of hands. 
was osteosclerosis, affecting especially cortical bone and more marked in the three fingers most severely affected by soft-tissue atrophic changes. Osteosclerosis is an unusual but recognized change in ischaemic digits, and arteriograms would have been informative in our case, but were refused by the patient.

Localized scleroderma (morphea) may occasionally be associated with certain sclerotic bone disorders such as melorheostosis, the soft tissue change corresponding to the distribution of the bone abnormality (Dillehunt \& Chuinard, 1936; Muller \& Henderson, 1963), but scleroderma with bound-down skin was not present in our case and the bone changes were not those characteristic of melorheostosis, in which the disorder is usually confined to the bones of one limb and there may be severe bone pain. There was no evidence of certain systemic conditions associated with increased bone formation, such as generalized osteopetrosis (Albers-Schönberg disease), osteopoikilosis, polyostotic fibrous dysplasia, lead poisoning and fluorosis.

It is of some interest that the clinical appear- ance of the left ulnar three fingers was suggestive of an ulnar nerve lesion, and that there was additionally reduction of sensory conduction velocity in the left ulnar nerve below the wrist, although in the presence of apparently frank muscle wasting other signs of neuropathy (reduced motor conduction velocity and electromyographic evidence of denervation of the muscles supplied) would have been expected. Assuming that an ulnar nerve lesion was present, it is possible to speculate that this occurred as a result of endarteritis of the vasa nervorum supplying the more distal fibres of the ulnar nerve, associated with the long-standing Raynaud's disease.

\section{References}

Allen, E.V. \& Brown, G.E. (1932) Raynaud's disease: a critical review of minimal requisites for diagnosis. Amer. J. med. Sci. 183, 187.

Dillehunt, R.B. \& Chuinard, E.G. (1936) Melorheostosis léri: a case report. J. Bone Jt Surg. 18, 991.

Müller, S.A. \& Henderson, E.D. (1963) Melorheostosis with linear scleroderma. Arch. Derm. 88, 142.

\section{Diabetes mellitus,}

\section{Addison's disease and pernicious anaemia}

\author{
R. C. TURner \\ M.A., M.R.C.P.
}

\author{
ARNOLD BLOOM \\ M.D., F.R.C.P.
}

Whittington Hospital, London, N.19

THESE three diseases in a patient are an unusual combination. That Addison's disease and pernicious anaemia may be associated with a disorder of autoimmune mechanisms raises the possibility of a similar association for diabetes mellitus. The evidence for this suggestion is discussed.

\section{Case history}

Mrs D.G., born 1901, developed vitiligo when aged 28, her hair went grey aged 40. In 1956 she first presented complaining of nervousness and fainting. She was markedly pigmented but Addison's disease was thought unlikely in view of obesity, raised blood pressure $(160 / 100 \mathrm{~mm}$ $\mathrm{Hg}$ ) and lack of buccal pigmentation. Since 1963 she had lost 3 stones in weight and later experienced increasing lightheadedness and fainting. In 1965 she was given a 2-month course of prednisone for lichen planus. She then developed thirst and polyuria and was found to have glycosuria. A $50 \mathrm{~g}$ glucose tolerance test whilst on $5 \mathrm{mg}$ prednisone/day revealed diabetes (fasting blood sugar $238 \mathrm{mg} / 100 \mathrm{ml}$ rising to a maximum of $270 \mathrm{mg}$, falling to $256 \mathrm{mg}$ after $2 \mathrm{hr}$ ). This responded to chloropropamide and later to dietary restriction alone. However, her pigmenta- 